\title{
Chinese President Chen Xujing's Academic Management and Christian Lingnan University
}

\author{
Jiang Chao ${ }^{1, a}$, Xia Quan ${ }^{2, b}$ \\ ${ }^{1}$ College of Liberal Arts, Jinan University, Guangzhou 510632, China \\ ${ }^{2}$ College of Liberal Arts, Jinan University, Guangzhou 510632, China \\ a540680594@qq.com, b txiaquan@jnu.edu.cn
}

\begin{abstract}
Keywords: Lingnan University; Chen Xujing ; Academic management.
Abstract. University president is the soul of a school, whose quality and ability are deeply related with the school development. The third Chinese president Chen Xujing of Lingnan University was a typical scholar-typed headmaster. In his office, Chen Xujing promoted free atmosphere, paid close attention to professor team construction and focused on implementing professors' management, which made Lingnan University recover from the loss of Anti-Japanese War and became one of the best universities. Chen Xujing's academic purport deeply affected his management strategies. Chen Xujing's focus on academic management was on the basis of both Zhong Rongguang and Li Yinglin's former hardworking, which was also rooted to Lingnan University's free academic discussion spirit under nonsectarian Christian background.
\end{abstract}

\section{Introduction}

President is the decision maker and executive of university, whose academic quality would have far-reaching influence on the university management strategies. Lingnan University's Chinese President Chen Xujing was a typical scholar-typed president of historians, sociologists, national experts and educators in a body. Chen Xujing (1903-1967), the words of Huaimin, was born in 1903, Wenchang County in Hainan Province, and served as Dean of Business College of the University of Southwest Associated University, the dean \&the director of the Economic Research Institute of Nankai University. As the third Chinese President of Lingnan University from August 1948 to 1952, Chen Xujing's deeply academic purport affected his management strategies. During his tenure of Lingnan University, Chen Xujing advocated academic generous tolerance, paid close attention to the construction of teaching staff, and focused on the implementation of professors.Lingnan University recovered from the loss of Japanese invasion and became one of the best universities. At present, the research on Chen Xujing and his relation with Lingnan University had made positive achievements ${ }^{[1]}$, but Chen Xujing's academic factors as scholar president was rarely mentioned. This paper makes a study on Chen Xujing's management strategies at Lingnan University from the perspective of his academic management.

\section{Advocating academic generous tolerance}

Chen Xujing had been working at Southwest Associated University for many years, as the dean of Law College and member of the University Council. The experience made Chen Xujing deeply experience and understand the inclusive academic atmosphere of Southwest Associated University. In August 1948, after being the president of Lingnan University, Chen Xujing stressed in the first open speech:"Advocating academic is the starting point of our efforts" [2]. Chen Xujing thought that university should have the academic atmosphere to discuss freely and not pay much attention to politics; real scholars should not only look at the material life, but also paid more attention to the ideological environment. As for the planning of Lingnan University, Chen Xujing paid attention to the creation of the academic atmosphere of freedom, adhering to the "Be written in their foreheads and show generous tolerance" management purpose ${ }^{[3]}$, especially advocating academic "Generous tolerance". Chen Xujing thought:"University is an institution of higher learning; academic development must be able to freely express their views and freely participate in the discussion; this will make the new 
invention and new things." [2] "Academic are in categories and have professionals; in order to pursue academic progress, the researchers must have sufficient time to study business and think independently. If there were no generous tolerance and scientific prediction, it is difficult to have significant academic progress and new development." [2]

As for Chen Xujing's academic "Generous tolerance", the first was in the respect and trust of professors. His son Chen Qijin memorized,Chen Xujing always gave full support for professors of how to study and how to teaching; neither attended teachers' lecture, nor checked their teaching and interfered professors' speaking contents. The professors' lecture contents were their research achievements, not what the books said. Chen Xujing had fully recognized professors' teaching level at appointment. Chen Xujing's respect and trust about professors was based on the full understanding of professors. As a liberal arts professor, once Chen Xujing had talked about a young professor of Science, casually could speak out "where he is from, coming from which schools and universities, the tutor as a graduate student and the title of the thesis." ${ }^{[4]}$ Because of understanding, trust and respect of the professors, most of the professors employed by Chen Xujing kept strict self-discipline and were strict with teaching work. Therefore, the teaching management formed the internal positive effect of no external constraints. ${ }^{[5]}$

Chen Xujing's academic "Generous tolerance" was a traditional free discussion of the spirit of Lingnan University. "The spirit of free discussion" was the important principle that was believed by Chen Xujing. Chen Xujing also strived to pursue it in practice. Beginning as president of Lingnan University, Chen Xujing mentioned in his precepts: "Although Lingnan University is a Christian University, it has no sectarian division and it is much focused on the spirit of free discussion." [2]. "Perhaps it's the reason of the kind of spirit. Lingnan University is willing to find a not baptized person to be the president, which is the initiative of Chinese University, and I am honored of it." ${ }^{[6]}$ Chen Xujing took the president of Lingnan University, further advocated the free discussion of the Lingnan spirit and promoted academic "Generous tolerance". Chen Xujing's attention to "Free discussion spirit" can also be reflected from his attitude towards Chen Yinque. Chen Xujing advocated "Whole Westernization". Chen Yinque was Chinese traditional literati, and didn't agree with Chen Xujing's idea of "Whole Westernization". However, the differences in personality and attitude were not hindered by the recognition of Chen Yinque. ${ }^{[7]}$ Based on "Free discussion spirit", Chen Yinque made the choice of teaching at Lingnan University.

With the guidance of academic "Generous tolerance", Lingnan University paid attention to the quality of personnel training, introduced western system and promoted the elite education. Chen Xujing thought "Lingnan University has a long history, beautiful campus and good study style, but we cannot say that we have reached an ideal position, so I think the academic is the starting point of our efforts." ${ }^{[8]}$ Because of this, Lingnan University's experimental training was more serious; although the standard of admission was low, it was difficult to graduate for students who are not excellent; so the level of graduates was very high, especially the students of Science and Engineering are much better. ${ }^{[9]}$ Teachers' assessment to students of Medical College was also very strict, so the punishment ratio of students was very high; the punishment ratio of other colleges was also not low. The academic atmosphere of Lingnan University had created the conditions for Liang Yusheng's growth. At Lingnan University, Liang Yusheng made the relationship with outstanding female professor Xian Yuqing, the poet known as "Women's second to none in South of the Five Ridges for thousands of years". Liang Yusheng was in the Department of Chemistry, but he was fond of literature. In junior year, Liang Yusheng served as the editor in chief of "Lingnan University Weekly" and published "Spring Song", "Lonely" and other popular prose poem. Solid writing skills brought up Liang Yusheng's novel writing good foundation. ${ }^{[10]}$ Liang Yusheng's novel creation had a very good relationship with the influence of good academic atmosphere of Lingnan University.

\section{Focusing on the implementation of "Professorial governance"}

Chen Xujing had a pet phrase: "I'm serving for the professor." ${ }^{[3]}$ Chen Xujing's important feature of managing Lingnan University was the implementation of "Professorial governance". "Professorial 
governance" was not the invention of Chen Xujing; among domestic universities at that time, president Cai Yuanpei of Peking University and Mei Yiqi of Tsinghua University had begun to implement "Professorial governance" in the 1920s. The idea of so called "Professorial governance" was professor played a decisive leading role in the decision-making and the management; administrative agency played the role of services or assistance; its essence was democratic management. ${ }^{[11]}$ Chen Xujing most paid attention to the role of professors in Lingnan University's development, and listened to the opinions of the professors. Chen Xujing took many measures to unite professors, not only let them become masters of Lingnan University, but also gradually established "Professorial governance" system.

Chen Xujing thought the president should be elected from professors. In the management, he changed Education Meeting into Council Meeting as the highest decision-making body of Lingnan University. In 1948 Lingnan University held the third executive meeting of Board of Directors and decided: "This year, the administrative organization should be simple, ......the Council Meeting didn't set up regular meeting; in addition to the president, provost, dean of students, dean of general affairs and directors of the College, the members of Education Meeting must have 8 elected professors,... the Education Meeting also didn't set up regular meeting, and original regular events of the Education Meeting was handled by the Council Meeting." ${ }^{[12]}$ If professors hadn't participated in the Education Meeting, the meeting records were not published. The Council Meeting reformed by Chen Xujing included the contents of Educational Meetings, and professors can also participate in decision-making; the records of each meeting were published at the latest Lingnan University Newspaper, so that teachers and students could understand Lingnan University's administration timely. The Council Meeting as the highest decision-making was factually a professors meeting. All major issues involving university affairs would listen to opinions of professors, and made the professors participate in administration with great power, rather than determined university affairs by administrative means.

Besides the Council Meeting, Chen Xujing soon established the Advisory Committee serving for the president, and members included: Feng Bingquan, Wu Ruilin, Wang Li and Foulon. Feng Bingquan was the representative of dean's office; Wu Ruilin was on duty of finance; Wangli was on behalf of Chinese teachers; Foulon was on behalf of foreign teachers. As the convener, Chen Xujing often exchanged into views with members, sometimes by phone, sometimes it was an interview. The issue raised by the committee was often the question that other meetings can't resolve. It was not the authority but an advisory body to the president. Its actual power included such issues as wages, employment, and critical issues involving with Lingnan University. ${ }^{[13]}$ The Advisory Committee gave full play to the role of the professors, which was conducive to mutual discussion when solving the key problems. Such as "Advisory Committee" had held three meetings in the first half of 1949, to discuss the question of whether Lingnan University should insist on running, finally according to wishes of the whole staff, deciding that Lingnan University "Don't withdraw, not dissolve and continue". [13]

Taking talent as standard was another example of Chen Xujing's implementation of "Professorial governance". Chen Xujing's policies to young scholars were flexible and strict. The assessment to professional title was not necessarily from the assistant experience, mainly depending on the ability and knowledge, but not ever studying abroad and the degree or a famous university. Once meeting with slightly qualified teachers to make application, Chen Xujing firstly must understand his academic and official experience. Then he thought the latter would not concentrate on teaching and probably made declination. Due to the selection of a number of outstanding talents, Chen Xujing could resolve practical questions quickly, and his thought of academic governance can also implement better. With Chen Xujing's efforts, all levels of people also leaded "By example to promote a rigorous style of study". The faculty of Lingnan University in a short time were strengthened quickly, which promoted Lingnan University's study style developing into a good direction, and Lingnan University's academic atmosphere was also more intense than before. 


\section{Paying close attention to the construction of professors' team}

Chen Xujing thought the number of professors decided whether a university could become first-rate ${ }^{[5]}$.In August 1948, Chen Xujing served as president of Lingnan University, at that time, Lingnan University was in the work of post-war restoration. The experts and scholars of various disciplines were insufficient; the academic atmosphere was not strong; some departments were lack of teachers; the research strength was weak. Chen Xujing made a plan for the introduction of well-known experts and professor based on the tense situation in the north of China. On December 8, 1948, Chen Xujing attended Lingnan University Board Meeting as observer and mentioned: "(1) I'm in the north for several months that universities in Tianjin and Peking were in a difficult situation but no tendency of moving into south of China. (2)Our universities' affairs plays out smoothly, due to the recent northern emergency situation many famous professors have the idea of going to south of China. Lingnan University want to take this opportunity to draw into professors who can contribute to Lingnan University's future development, otherwise the opportunity will now come and go at once." ${ }^{[14]}$ Chen Xujing's accurate grasp of the situation made Lingnan University occupy the preemptive opportunity of talents introduction.

Implementation of the program was very important. Chen Xujing took the shuttle in the north and south of China to recruit first-class scholars for Lingnan University. The most striking action was the introduction of historian Chen Yinque and the mathematician Jiang Lifu, who were key experts whom the national government want to called to Taiwan. On January 19, 1949, Chen Yinque arrived in Guangzhou.Chen Xujing invited him to teach at Lingnan University. At that time Chen Yinque had already been blind; in order to let him concentrate on research, Chen Yinque didn't only provide him with the satisfactory assistant, but also specifically promised him not to participate in university activities. ${ }^{[3]}$ Chen Xujing created a quiet learning environment for Chen Yinque of "The pursuit of freedom, the spirit of independence". Jiang Lifu, the doyen of mathematics, was originally the director of "The Center of the Mathematics Institute in Taiwan". ${ }^{[13]}$ With the invitation of Chen Xujing, in July 1949, Jiang Lifu who thought himself "Firstly don't understand Cantonese; don't believe in Christianity; was not fitting for the environment of Lingnan", left Taiwan for Lingnan University in Guangzhou by the excuse of making work report to National Government. Due to the arrival of Jiang Lifu, the Science and Technology College of Lingnan University set up the Mathematics Department in the same year, Jiang Lifu as the director. ${ }^{[2]}$

Only a month after Chen Xujing as the president of Lingnan University, the director of the National Institute of Sun Yat Sen University, the famous linguists Wang Li came to Lingnan University. With Chen Xujing's efforts, medical radiology expert Xie Zhiguang of Peking Union Medical College Hospital came to Lingnan University, and Xie Zhiguang contacted several distinguished professors of medicine such as surgery expert Situ Zhan and bacteriologist Bai Shien etc. ${ }^{[15]}$ On October 14, 1949, the 103rd "Lingnan University Newspaper" on the front page published Chen Xujing's "Recent years of Lingnan University". It made details of Chen Xujing's efforts of drawing back professors since being president for a year, in addition to the above mentioned Chen Yinque, Jiang Lifu, Wang Li, Xie Zhiguang, Situ Zhan and Bai Shien, there were others such as: Liang Fangchung, Wu Daye, Wang Zhengxian, Peng Yuxin, Zhang Chunming, Li Qi, Zhou Qixun, Yang Chingkun, Cen Jiawu, Gui Mingjing, Chen Yongling, Tao Baokai, Qin Guangyu, Kuang Ronglu etc. ${ }^{[8]}$ With the original scholars, Li Peiwen, Tang Zeguang, Chen Jiping, Rong Geng, Zhuang Zexuan and Chen Hanbiao ${ }^{[8]}$, Lingnan University gathered many famous scholars for a time.

Chen Xujing concerned about every aspect of teachers. Chen Xujing often went to Chen Yinque's home showing condolences to solve practical difficulties. Chen Xujing organized medical experts make regular physical examination, hoping for being able to cure Chen Yinque's blindness. When Chen Xujing presided over the affairs of Lingnan University, Guangzhou was the last political center of National Government in main land; dignitaries were gathering and some of them were flirting with Lingnan University to ask for helps. For example Chiang Kai Shek, He Yingqin had made invitations or requested a temporary settlement, which were avoided and declined by Chen Xujing.For Chen Xujing was not willing to interfere with academic by Politics. However, Chen Xujing had to turn to Zhu Jiahua for help to rescue Li Peiwen, the Dean of Agricultural College ${ }^{[16]}$. The heart of protecting professors 
was evident. Chen Xujing also took care of staff very much. Employees and their families can enjoy regular free medical care; children can attend free elementary school, middle school; which thereby eliminated the worries of the teachers.

Under Chen Xujing's management, Lingnan University gathered a galaxy of talents with a new look. Chen Xujing's key managing sill was "On the one hand, grasp the funds; on the other hand, the professor". Funding is the key to the development of university. Sufficient fund can ensure the stability of the teaching team. During Chen Xujing's presidency, Lingnan University faced with serious financial crisis. The financial crisis had brought great pressure and challenge to President Chen Xujing of Lingnan University. Chen Xujing always took the financial issues as the top priority of the development. Nonetheless, Lingnan University had always maintained a normal operation and ensured professors get paid on time. ${ }^{[17]}$ It's related with Chen Xujing's actively running to raise funds. At the same time, Chen Xujing changed the ideas of fund management. In order to avoid the domestic inflation, Chen Xujing changed donations and funds into gold bullion to maintain value, and then cashed gold bullion into Hong Kong dollar to pay for salary. ${ }^{[16]}$ This approach ensured wages' real purchasing power. With Chen Xujing's efforts, Lingnan University was no serious budget crisis, and National Sun Yat Sen University once broke out strike event for the shortage of funds. ${ }^{[17]}$ Because of funds were guaranteed, when Minister of Education and Finance Minister of National Government took annual salary of $\mathrm{HK} \$ 10$ million and new villa and other conditions to invite Chen Yinque personally, Chen Xujing immediately expressed: "I will give HK\$10 million and build new houses for them to live." ${ }^{33]}$

\section{Conclusion}

Establishment of the academic governance idea is an important prerequisite to ensure the accomplishment of the four university missions as personnel training, scientific research, social services and cultural inheritance. As top decision-makers and the executive, president's attitude towards academic determines the direction of the university. Chen Xujing was a scholar and had strong academic interest, and once worked in Southwest Associated University. The experiences caused him recognize academic management deeply. With the sober mind, excellent ability of grasping the opportunity, Chen Xujing took academic management successfully, as well as Lingnan University's good tradition retaining from the former Chinese Presidents Zhong Rongguang and Li Yinglin. With the guidance of academic governance strategy, Chen Xujing advocated academic generous tolerance, focused on the implementation of "Professorial governance", and paid close attention to the construction of professors' team, which ensured professors dare to pursue the truth not trapped by external factors courageously ${ }^{[18]}$, creating a strong free academic atmosphere. As a result of the implementation of the academic management, the professor team of Lingnan University was more stable; professors' ability of participating university management was played fully. After one year's presidency of Chen Xujing, Lingnan University didn't only gradually improve the teaching facilities, but also increased the level of academic standards. The number of students increased significantly. For example, at the second semester in 1948, Lingnan University had a total of 1,430 students, increasing by 376 in 1947, which was the highest number in university history. Chen Xujing's striving promoted

Lingnan University to stride forward the direction of the domestic first-class university. ${ }^{[2]}$.Chen Xujing's academic management was obvious.

\section{Acknowledgements}

This thesis was supported by Jinan University Humanities and Social Sciences Project "Pilot Project of Jinan" (No. 15JNLH002).

\section{References}

[1]On the study of Chen Xujing, representative works are as follows: Liu Jilin. Chen Xujing:Culture and Idea Research[M] . Tianjin People's Publishing House, 2003; Tian Tong.Chen Xujing's Research 
on the Current Situation and Breakthrough [J]. Journal of Huazhong Normal University (SOCIAL SCIENCE EDITION), 2004(5); Xia Quan.Chen Xujing and Jinan University[J].Southeast Asia Research, 2004(2); Zhao Libin. The Differences between the North and the South in View of East and West: Chen Xujing's Southern Culture Idea [J]. History Monthly, 2005 (1); Zhang Shibao. Review on Chen Xujing's Individualism [J]. Guangdong Social Science.2006 (4); Wang Zhenxi.The Clash of Civilization from the Perspective of Social Ethics: Take Liang Shuming and Chen Xujing as the Center [D]. Fudan University PhD Thesis in 2007. On the study of Chen Xujing and Lingnan University, the representative works are as follows: Tan Huosheng.Chen Xujing and Lingnan University[J]. People, 2007(9); Wang Shaling.On Chen Xujing and Lingnan University (1948-1952) [D]. Jinan University Master Degree Thesis in 2006 etc.

[2]Tan Huosheng.Chen Xujing and Lingnan University [J]. People, 2007(9).

[3]Zhi Xiaomin. Psychological Single Room [M]. Changchun Press, 1997, pp. 29-30.

[4]Duan Muzheng.The President Good at Uniting Intellectuals of Chen Xujing [G] // Chen Chuanhan. The Awakening of the East: Chen Xujing Symposium Anthology.Yanbian University Press, 2000, pp.90-91.

[5]Zhang Taiyuan. Higher education Thought and Practice of Chen Xujing[J].Journal of Liaoning Normal University (SOCIAL SCIENCE EDITION), 2001(3).

[6]Chen Xujing. The Speech at Teachers and Students Welcome Meeting [N]. Lingnan University Newspaper (82nd). 1948-9-20(1).

[7]Lu Jiandong.The Last Twenty Years of Chen Yinque [M]. SDX Joint Publishing Company, 1996, pp.28.

[8]The Most Recent Year Lingnan University [B].Lingnan University Archives in Guangdong Provincial Archives: 38/1/87.

[9]Feng Bingquan.Memories of Lingnan University [M] //Zhong Shuhe and Zhu Chun.The Past Universities: Memoirs. Hunan Education Press, 1982.

[10]Yang Jianbing.Swordsman out of the Lingnan University [M] //The University Refused to Mediocrity: A Perspective of College Students in the Course of Struggle. China Financial and Economic Publishing House, 2003, pp. 105-106.

[11]Shang Min.The Interpretation of Southwest Associated University [J]. Contemporary Education Forum, 2007 (8).

[12]The Third Regular Meeting Records of Board of Governors at 37th Year of the Republic of China [B]. Lingnan University Archives in Guangdong Provincial Archives, 38/1/20.

[13]Yao Shuhua. The Road of Professor Feng Bingquan [M]. Southern China Institute of Technology, 1987, pp. 75-78.

[14]Annual Meeting Records of Board of Governors at 37th Year of the Republic of China [B]. Lingnan University Archives in Guangdong Provincial Archives, 38/1/20.

[15]The Medical College Employed Many Professors This Year [B]. Lingnan University Archives in Guangdong Provincial Archives 38/1/87.

[16]Situ Yun. The Old Things of Chen Xujing at Lingnan University [N]. People's Political Consultative Conference, 2008-10-16.

[17]Lin Yuan. Recalling Patriotic Scholar Mr. Chen Xujing [G] //The50th Anniversary Memorials of the National Southwest Associated University. Beijing: Chinese Literature Press, 1988,144. 
[18]Sui Ifan. Academic Freedom and University Presidents Management [J]. Tsinghua University Education Research, 2001(3). 